\title{
Multi-scale analysis on soil improved by alkali activated binders
}

\author{
Enza Vitale $^{1,{ }^{*}}$, Giacomo Russo ${ }^{1}$, Dimitri Deneele ${ }^{2,3}$ \\ ${ }^{1}$ Department of Civil and Mechanical Engineering, University of Cassino and Southern Lazio, Italy \\ ${ }^{2}$ Institut des Matériaux Jean Rouxel (IMN), Université de Nantes, CNRS, France \\ ${ }^{3}$ IFSTTAR, Institut Français des Sciences et des Technologies des Transports, de l'Aménagement et des Réseaux, France
}

\begin{abstract}
In the present paper, the use of alkali activated binders to improve engineering properties of clayey soils is presented as an alternative to traditional binders such as lime or cement. An alkali-activated fly ash and its chemo-physical evolution has been monitored at increasing curing times by means of X-Ray Diffraction and Scanning Electron Microscopy. Alkali-activated binder has been mixed with soil for evaluating the improvement of its mechanical behaviour. One-dimensional compression tests on treated samples have been performed with particular reference to effects induced by binder content and curing time. Test results showed a high initial reactivity of the alkali activated systems promoting formation of new mineralogical phases responsible of the mechanical improvement of the treated soil.
\end{abstract}

\section{Introduction}

The development and the use of environmentally friendly binders as an alternative solution to traditional binders such as lime or cement in a low carbon agenda is of prime importance particularly in the construction sector. The use of novel and efficient binders for geotechnical applications is a promising issue in terms of sustainability since it reduces the carbon footprint and allows reusing secondary by-products such as artificial pozzolans. These by-products can be involved in soil improvement as cementing agents if properly activated, inducing a mechanical improvement of natural soils, not suitable for construction purposes.

Alkali activated binders represent a viable, sustainable alternative to the use of ordinary stabilizing agents for soil improvement [1]. Differently from the use of lime and cement for soil improvement [2-5], experimental research about the use of alkali activated binders in soil improvement is still limited; nevertheless, recent studies highlight the relevant potential of novel binders for geotechnical purposes. Cristelo et al. [6] researched the optimum fly ash - based alkaline activated binder for the improvement of soil to be used in rammed earth construction through a parametric analysis using laboratory tests. Rios et al. [7] compared the mechanical behaviour of samples of sand improved by an alkali activated fly ash binder and the similar samples improved by cement, highlighting the effectiveness of the alkali activated binders in increasing the shear strength properties of the soil.

Alkaline activation of by-products is the consequence of a chemical reaction between an aluminosilicate source with an alkaline solution (i.e. sodium hydroxide, sodium silicate). The aluminosilicate source is formed by precursor materials like natural pozzolan (e.g., pyroclastic soils), or artificial pozzolans (e.g., fly ash, silica fume, steel sludge). The chemo-physical evolution occurring after the activation promotes the formation of cementitious compounds [8-9]. The reaction mechanism is promoted by the alkaline solution, which enables the dissolution of the aluminosilicate source (precursor) and the subsequent precipitation of gel phases, which condense in a three-dimensional aluminosilicate network [10-12].

In the present study, an insight into the alkaline activation of an artificial pozzolan (fluidal bed combustion fly ash) and its effects on the improvement of the mechanical behaviour of a clayey soil have been reported. A multi scale analysis have been performed to highlight the link between the ongoing reactions and the macroscopic evolution of soil properties. The chemophysical evolution of the binder has been monitored at increasing curing times by means of X-Ray Diffraction analysis and Scanning Electron Microscopy (SEM). The macroscopic behaviour of the alkali-activated binder treated soil has been investigated by means of onedimensional compression tests. The effects of binder content and curing time on the mechanical performance of treated samples have been considered.

\section{Material and experimental procedures}

\subsection{Material}

The artificial pozzolan used in the present work is a fluidal bed combustion fly ash supplied by a power plant located in Italy. Raw material is composed by vitreous and crystalline phases, which include calcium-containing minerals (anhydrite, calcite) and other minerals (quartz,

\footnotetext{
* Corresponding author: e.vitale@unicas.it
} 
hematite). The chemical composition of fly ash is reported in Table 1 .

The sodium silicate solution was supplied by Woellner (Germany) with a $\mathrm{SiO}_{2} / \mathrm{Na}_{2} \mathrm{O}$ mass ratio of 1.7 .

Speswhite kaolin from deposits in the South West of England was the soil considered for the experimental investigation. The specific gravity $\mathrm{G}_{\mathrm{s}}$ is 2.6 and its surface area, determined by BET, is $14 \mathrm{~m}^{2} / \mathrm{g}$. The $\mathrm{pH}$ value is 4.6 and plastic limit and liquid limit are respectively $32 \%$ and $70 \%$, with a plasticity index IP equal to $38 \%$. X-Ray diffraction pattern is shown in Figure 1 . The soil is manly composed of kaolinite clay minerals with small amounts of quartz and muscovite. The chemical composition of the soil is given in Table 2 .

Table 1. Chemical composition of fly ash.

\begin{tabular}{|c|c|}
\hline Constituent & Percentage (\%) \\
\hline $\mathrm{SiO}_{2}$ & 19.80 \\
\hline $\mathrm{Al}_{2} \mathrm{O}_{3}$ & 39.4 \\
\hline $\mathrm{CaO}$ & 5.2 \\
\hline $\mathrm{K}_{2} \mathrm{O}$ & 1.8 \\
\hline $\mathrm{Fe}_{2} \mathrm{O}_{3}$ & 7.14 \\
\hline
\end{tabular}

Table 2. Chemical composition of Speswhite kaolin.

\begin{tabular}{|c|c|}
\hline Constituent & Percentage (\%) \\
\hline $\mathrm{SiO}_{2}$ & 53.80 \\
\hline $\mathrm{Al}_{2} \mathrm{O}_{3}$ & 43.75 \\
\hline $\mathrm{CaO}$ & 0.02 \\
\hline $\mathrm{K}_{2} \mathrm{O}$ & 1.45 \\
\hline $\mathrm{TiO}_{2}$ & 0.05 \\
\hline
\end{tabular}

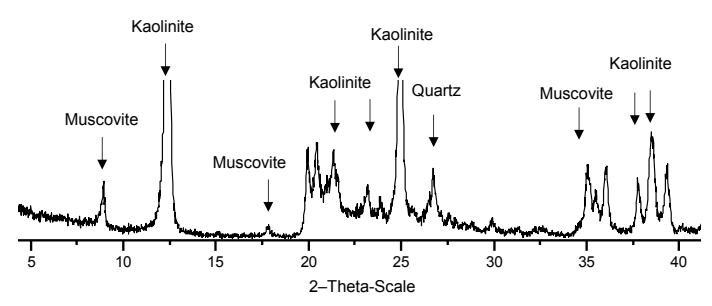

Fig. 1. X Ray diffraction pattern of Speswhite kaolin.

\subsection{Samples preparation}

Alkali activated binder (FA100\% in the following) was prepared by mixing fly ash, alkaline solution and water in fixed proportions. Alkaline solution/fly ash mass ratio was kept constant and equal to 0.5 . Additional deionised water was provided to the system in order to guarantee an effective mixing and a sufficient liquid phase amount for the dissolution of aluminosilicate source. The deionised water/solid ratio, by mass, was selected equal to 0.5 . Soil samples treated with alkali-activated binder were prepared by considering increasing fly ash percentages equal to $20 \%$ (sample KF20\%), and $40 \%$ (sample KF40\%) by dry weight of solids (soil+ fly ash), and alkaline solution /fly ash mass ratio equal to 0.5 . The initial water content added to the mixtures was equal to the liquid limits of the treated samples. Remoulded samples were prepared for oedometer tests by hand mixing solids (fly ash + soil), alkaline solution and water at their liquid limit (i.e. $\mathrm{w}_{\mathrm{L}}=60 \%$ for $\mathrm{KFA} 20 \%, \mathrm{w}_{\mathrm{L}}=55 \%$ for KFA40\%). Samples were poured in the mould and placed in oedometer cell without compaction. The treated samples were then sealed in plastic bags and cured at increasing curing times of $24 \mathrm{~h}, 28$ and 60 days before performing mechanical tests.

\subsection{X-Ray diffraction analysis}

Mineralogical composition of samples was investigated by X-Ray analysis performed on randomly oriented powder using a Brucker AXS D8 Advance Diffractometer with $\mathrm{CuK} \alpha(\lambda=0.154 \mathrm{~nm})$ radiation and a step size of $0.017^{\circ}$. Samples were dehydrated before testing by freeze-drying technique [13]

\subsection{Scanning Electron Microscopy (SEM)}

Surface state modifications of samples due to alkaline activation process have been examined through Scanning Electron Microscopy (SEM) by using Hitachi SU5000 microscope. Raw and treated samples have been dehydrated by freeze-drying technique. A pre-treatment gold coating has been applied for SEM observations.

\subsection{One-dimensional compression tests}

One-dimensional compression tests have been performed on alkali activated samples cured for 24 hours, 7 and 28 days. Tests have been performed in standard oedometer cells, where vertical stress was conventionally applied in successive steps $\left(\Delta \sigma_{\mathrm{v}} / \sigma_{\mathrm{v}}=1\right)$ within the stress interval 10 $\div 2400 \mathrm{kPa}$. Micrometer dial gauges with an accuracy of $0.001 \mathrm{~mm}$ have been used to measure vertical displacements.

\section{Results}

X-Ray diffraction patterns of raw and alkali activated fly ash binder (FA100\%) are shown in Figure 2. Mineralogical composition of fly ashes is modified by alkaline activation process. Consumption of crystalline phases such as anhydrite $\left(\mathrm{CaSO}_{4}\right)$ and aluminate phases $\left(\mathrm{MgAl}_{2} \mathrm{O}_{4}\right)$ is evidenced by disappearance of their characteristic peaks after 60 days of curing. Precipitation of new mineralogical phases such as thenardite $\left(\mathrm{Na}_{2} \mathrm{SO}_{4}\right)$ seems to be consistent with the release of sulphate from anhydrite dissolution and its subsequent reaction with sodium provided by silicate solution. A broad reflection between $25^{\circ}$ and $35^{\circ}$, corresponding to new poorly crystalline compounds resulting from alkaline-activation reactions, was observed in alkali activated fly ash after 60 days of curing. SEM observations on raw and alkali activated fly ash after 60 days of curing are shown in Figures 3 and 4. The raw sample is characterised by particles of different shape and size. The vitreous phase is made of some bigger grains (Figure $3 \mathrm{a} ; 3 \mathrm{~b}-2 ; 3 \mathrm{c}$ ), spherical particles (Figure 3b-1) and aggregate of small particles (Figure 3b-3). A coating of gel hydrates 


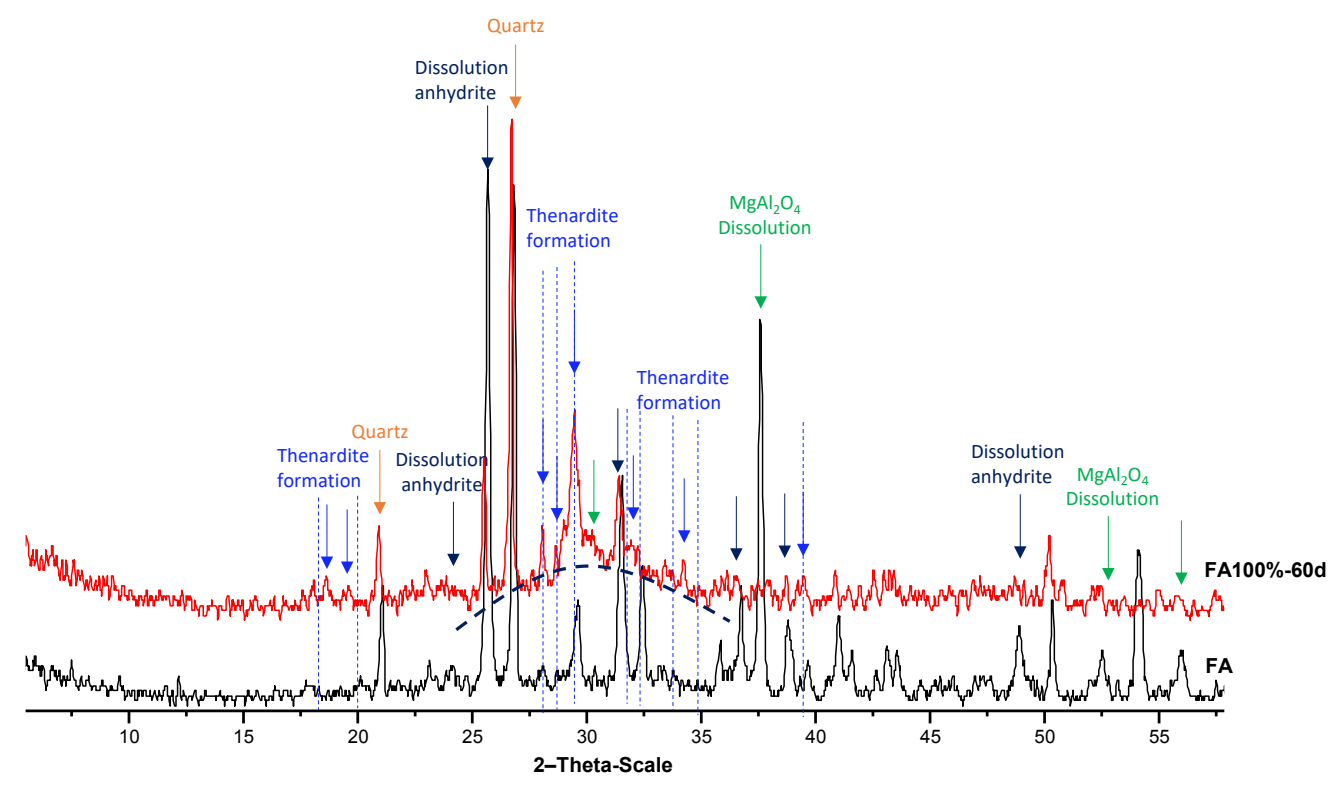

Fig. 2. X Ray diffraction patterns of raw fly ash and alkali activated fly ash (FA100\%) at 60 days of curing time.
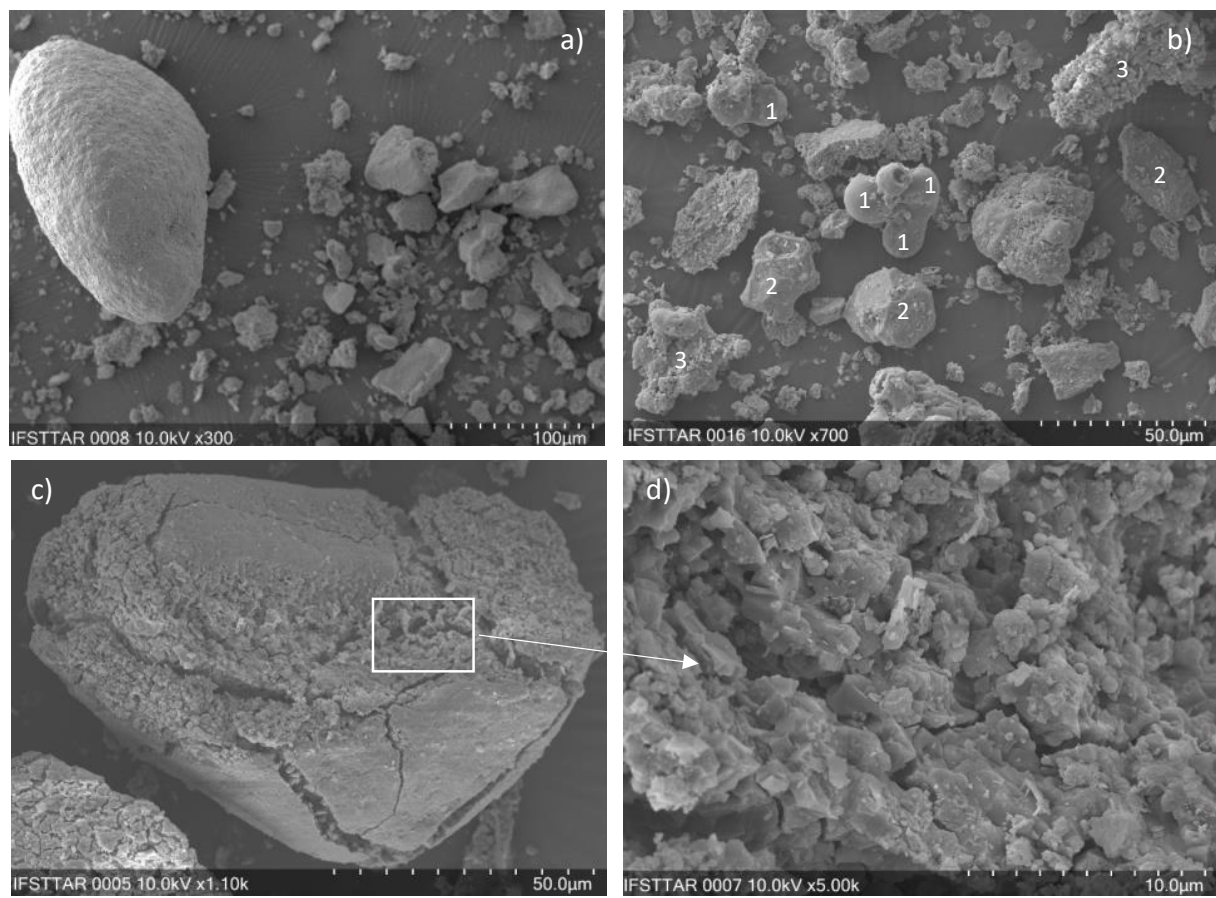

Fig. 3. SEM observations of raw fly ash. 

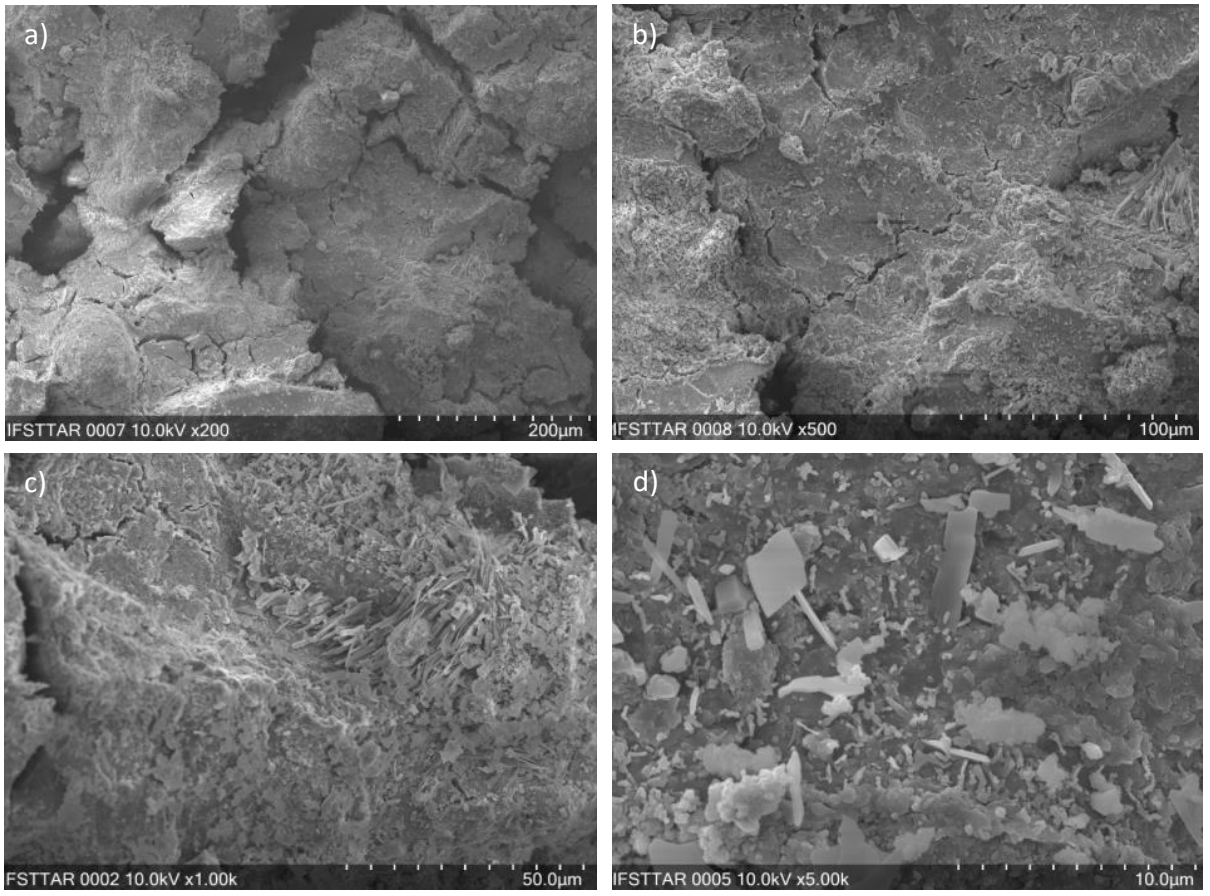

Fig. 4. SEM observations of alkali activated fly ash at 60 days of curing.

on particles surface is observed at 60 days of curing (Figure $4 \mathrm{a}, \mathrm{b}$ ). After the treatment, surface state of the sample is clearly modified. The alteration of glassy/vitreous phases induced by the alkaline environment is clearly evidenced by SEM on raw and alkali activated samples at higher magnifications (Figure $3 d$ and $4 d)$.

1D compressibility curves of alkali activated binder treated soil (KFA40\%) at increasing curing times, namely 24 h, 28 and 60 days are reported in Figure 5. Addition of alkali activated binder induces an overall reduction of compressibility of treated samples, with reduced volume strains for reference vertical stresses. The reduction is more relevant for increasing curing times, showing the stiffer behaviour of treated samples although the behaviour of treated samples does not evolve with time after 28 days of curing. Coupled with reduction of compressibility, all the samples show an increase of yield stress. Transition from a reversible behaviour to an irreversible one is shifted (yield stress) to higher vertical stresses, inducing an advantageous behaviour of the improved material for construction purposes. In Figures 6 , compressibility curves of treated samples are reported as function of binder contents. KFA samples prepared at $20 \%$ and $40 \%$ of alkali activated fly ash binder (KFA20\% vs. KFA40\%) and cured for 24 hours before testing (Figure 6a) show no relevant changes in the compressibility curves. The improvement of mechanical response of treated samples after 28 days of curing is more relevant when increasing the amount of binder; both reduction of compressibility and yield stress increase depend on binder content. Differently from the shorter curing time, the post-yield behaviour shows an increased slope of the curve, highlighting a more evident destructuration of the samples at increasing vertical stresses. A comparison between mechanical performance induced by alkali activated binder (KFA40\%) and ordinary Portland cement $(\mathrm{KC} 40 \%)$ has been shown in Figure 7 for samples prepared with the same binder content and cured for 60 days, in order to highlight the role of type of binder on the mechanical improvement of treated soil. Results show a higher compressibility reduction and yield stress increase for KFA treated samples compared to cement treated samples $(\mathrm{KC} 40 \%)$. For stress levels higher than yield stress, cement treated samples show a higher compressibility coefficient (i.e. slope of the compressibility curve) with respect to alkali-activated samples, depending on the de-structuration stage induced by load increase. Stress levels achieved during the tests were not high enough to induce the complete destructuration of both treated samples.

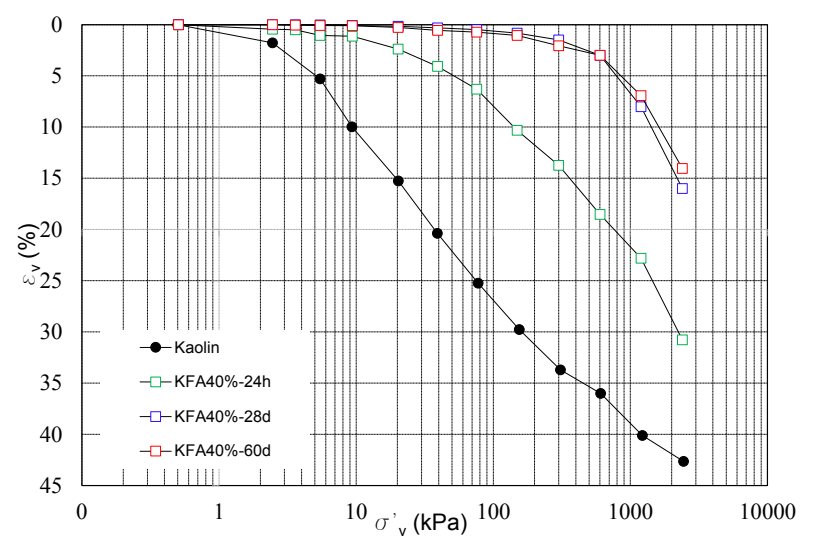

Fig. 5. One-dimensional compression tests on untreated and KFA $40 \%$ treated kaolin as function of curing time. 

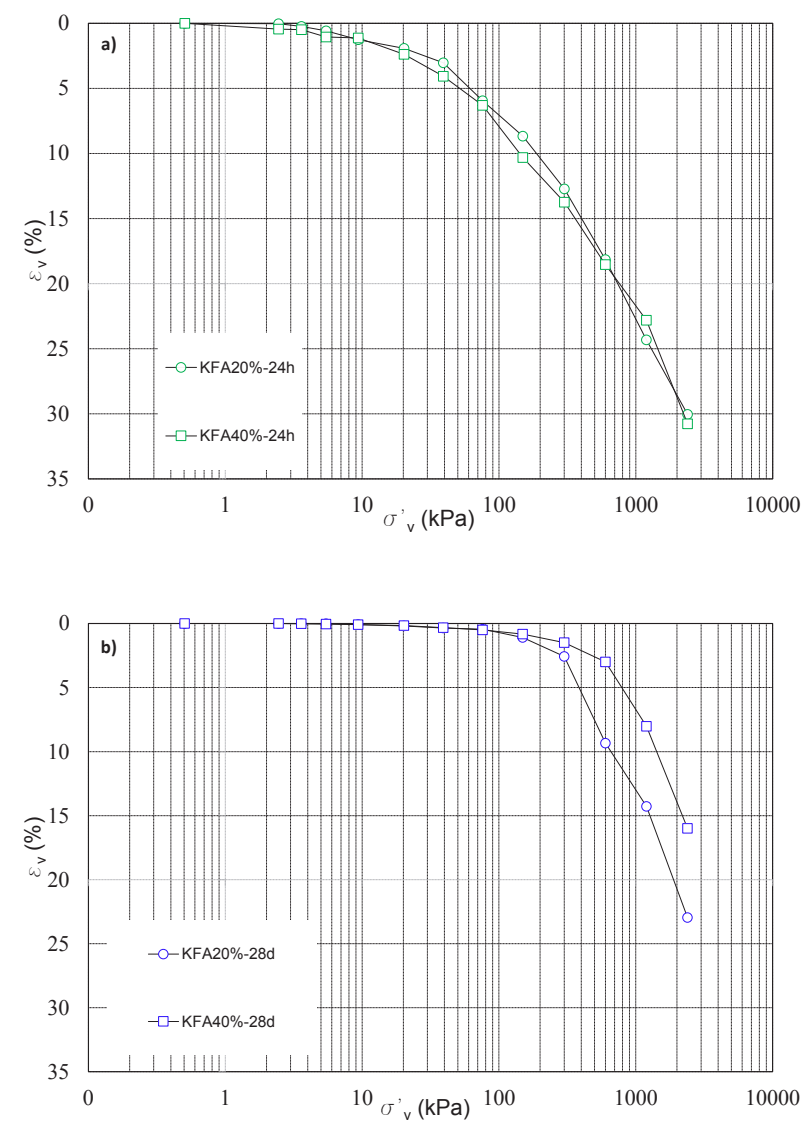

Fig. 6. One-dimensional compression tests on treated samples as function of binder content - KFA20\% vs. KFA40\%: a) $24 \mathrm{~h}$ of curing; b) 28 days of curing.

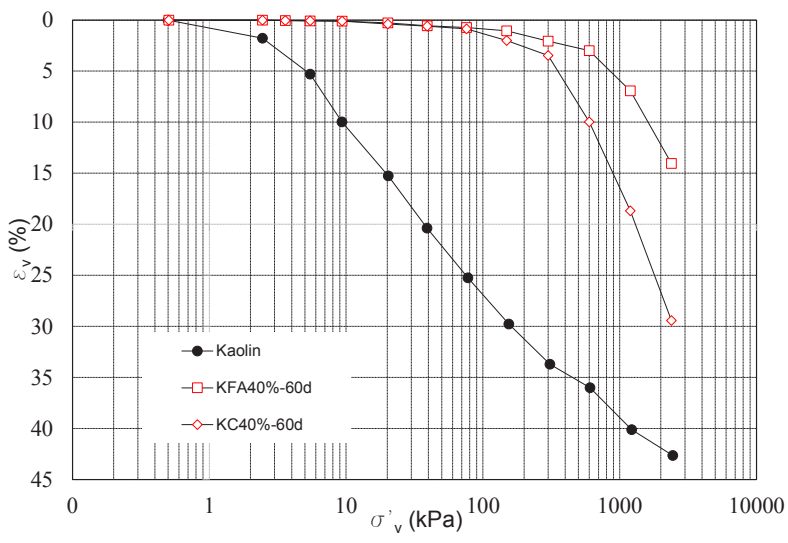

Fig. 7. One-dimensional compression tests on treated samples as a function of type of binder (KFA40\% vs. $\mathrm{KC} 40 \%$ ) at 60 days of curing.

\section{Conclusions}

An insight into the mechanical improvement induced by an alkali-activated binder based on the activation of a fly ash on a clayey soil has been presented. The experimental multiscale investigation on the chemo-physical evolution of the binder show the high reactivity of the alkali activated fly ash to dissolve the aluminosilicate source and to promote the precipitation of new mineralogical phases with cementitious properties. Experimental evidences at microscale have been linked to the macroscopic behaviour of a treated soil. One-dimensional compression tests performed on treated sample highlight the effectiveness of alkali activated binder to promote an improvement of the mechanical behaviour of treated soil. An increase of the compressive strength and of the yield stress soil was observed since the very short term, whose extent depends on curing time and binder contents. The efficiency of treatment has been highlighted by comparing the mechanical performance induced by alkaliactivated binders with the one promoted by ordinary Portland cement. A marked improvement of the mechanical behaviour of soil is induced by alkaliactivated binder, representing a viable, sustainable alternative to the use of ordinary stabilizing agent for soil improvement

\section{References}

1. A. Wilkinson, A. Haque, J. Kodikara, Proc Inst Civ Eng - Ground Improv. 163, 3 (2010)

2. E. Vitale, D. Deneele, G. Russo, G. Ouvrard, Appl. Clay Sci. 132, pp. 223-231 (2016)

3. E. Vitale, D. Deneele, M. Paris, G. Russo, Appl. Clay Sci. 141, pp. 36-45 (2017)

4. G. Guidobaldi, C. Cambi, M. Cecconi, D. Deneele, M. Paris, G. Russo, E. Vitale, Eng. Geol. 221, pp. 193-201 (2017)

5. G. Guidobaldi, C. Cambi, M. Cecconi, P. Comodi, D. Deneele, M. Paris, G. Russo, E. Vitale, A. Zucchini, Eng. Geol. 245, pp. 333-343 (2018)

6. N. Cristelo, S. Glendinning, A.T. Pinto, Ground improvement 164, pp.73-82 (2011)

7. S. Rios, N. Cristelo, A. V. da Fonseca, C. Ferreira, J. Mater. Civ. Eng. 28, 2 (2016)

8. J. Davidovits, J Therm Anal 37, pp. 1633-1656 (1991)

9. H. Xu, J.S.J. van Deventer, Int J Miner Process 59, pp. 247-266 (2000)

10. P. Duxon, A. Fernàndez-Jiménez, J. L. Provis, G. C. Lukey, A. Palomo, J. S. J, van Deventer, Journal of Materials Science 42, 9 (2007)

11. J. L. Provis, J. S. J. van Deventer, Vol.13. RILEM State of the Art Reports. Dordrecht: Springer Netherlands (2014)

12. P. Sargent, P. N. Hughes, M. Rouainia, M. L. White Eng Geol. 152, 1 (2013)

13. P. Delage, F. M. Pellerin, Clay Miner. 19, 2 (1984) 